\title{
Fuzzy Statistical Process Control of a Calcite Grinding Plant Using Total Color Difference Parameter $(\square$ E)
}

\author{
Metin Uçurum \\ Industrial Engineering Department, Bayburt University. Bayburt-Turkey
}

\begin{abstract}
Statistical process control (SPC) is one of the important approaches used in quality management. SPC can be applied in plants to obtain good quality and high standard products that have become very popular in many industries. Fuzzy process capability analysis by using X-R control charts gives more realistic results, developed with fuzzy theory. Fuzzy control charts are more sensitive than SPC. Therefore, fuzzy control charts lead to producing better-quality products. In this study, total color difference parameter $(\Delta \mathrm{E})$ was studied using fuzzy observation on a calcite grinding plant products. For this purpose, color parameters of the grinding plant products were evaluated using triangular fuzzy number (TFN) and fuzzy process capability indices (PCIs). The results show that the mill plant seems to be under control. Therefore, on a randomly selected sample used in the fuzzy statistical process control work was chosen and other color parameters such as whiteness index (WI), saturation index $(\mathrm{SI})$, hue angle $(\mathrm{H})$, browning index $(\mathrm{BI})$ and yellowness index $(\mathrm{YI})$ and particle size properties, XRF, XRD, FTIR, TGA-DTA and SEM were then determined on the calcite sample.
\end{abstract}

Keywords: Fuzzy Statistical Process Control, X-R Charts, Grinding plant, Total color difference

\section{INTRODUCTION}

One of the predominant technologies in mining, production of minerals. and materials treatment is grinding. Ball mills are mainly used for that purpose [1]. Grinding by collision is more effective for size reduction of brittle materials. One of the few machines for grinding of materials by collision is a disintegrating mill-disintegrator [2], a mill for reducing lump material to a granular product. where crushing took place partly by direct impact and partly by interparticulate attrition [3]. Ground and precipitated calcium carbonates are widely used as performance minerals in the rubber, plastics and paper industries. Both untreated and surfacemodified forms are used. depending upon the nature of the end product [4]. In polymer applications the calcium carbonate is often blended with polypropylene (PP) homopolymer or polyethylene (PE) to improve processability and properties such as stiffness and impact resistance of composite materials. For effective mixing and good adhesion characteristics it is desirable that the surface energies of the mineral and polymer are close to each other [5].

The aspect and color of the calcite surface is the first quality parameter evaluated by consumers and is critical in the acceptance of the product. Industrial applications require specific properties and characteristics. Among the most valuable characteristics is the color, a function of the parent rock and its alteration [6]. In polymineral natural samples with complex crystallochemistry, the study of color is more complicated than in minerals of high purity (or even synthetic ones) where diffuse reflectance spectroscopy techniques are employed [7]. An organization called the Commission International Eclairage (CIE) determined the standard values that are used worldwide to measure color. The values used by CIE are called $\mathrm{L}^{*}, \mathrm{a}^{*}$, and $\mathrm{b}^{*}$ and the color measurement method is called CIELab. Symbol L* represents the difference between light (where $\mathrm{L}^{*}=100$ ) and dark (where $\left.\mathrm{L}^{*}=0\right) \mathrm{a}^{*}$ represents the difference between green $\left(-\mathrm{a}^{*}\right)$ and red $\left(+\mathrm{a}^{*}\right)$. and $\mathrm{b}^{*}$ represents the difference between yellow $\left(+\mathrm{b}^{*}\right)$ and blue $\left(-\mathrm{b}^{*}\right)[8]$.

Statistical process control (SPC) concept has become very important in chemical and manufacturing industries. Its objective is to monitor the performance of a process over time in order to detect any special events that may occur. By finding assignable causes for them, improvements in the process and in the product quality can be achieved by eliminating the causes or improving the process or its operating procedures [9]. The use of statistical process control techniques in mineral processing plants is as important as in many other industries, as management aims for a certain quality, which will enhance reputation and future progress. Control charts are among the most effective means for controlling process control systems via statistical methods in an economical and secure way. Control charts are used for determining quantitative and qualitative variations that occur in a process over a certain time frame [10]. To use a control chart such as the X-chart to monitor the process mean or the R-chart to monitor variability, samples are taken over time and values of a statistic are plotted [11]. Control chart type X-R is a very important quality tool. Its determined statistical measures are recorded properties of 
products obtained as a result of inspections taken randomly from the samples of products in the determined place of the process. The aim of control chart type X-R is to observe and register the changing ability of the characteristics of the researched element of the production process. The example of implementing control chart type X-R shows the possibility of monitoring parameters of the production process according to an idea of defect prevention. Using this method allows monitoring the production process, provides opportunities for cost reduction, and maintains the production process stability [12].

Conventionally, for monitoring a manufacturing process, the Shewhart control charts are applicable on the condition that collected sample data are real-valued numbers only. However. in many cases the key quality characteristic of manufactured products, such as the color-intensity quality of produced pictures or screens and the reading-precise quality shown on analogue measurement equipments, apparently inheres with imprecise character, whose samples data are collected by taking certain imprecise information into consideration, known as interval-valued or fuzzy numbers/data $[13,14]$. Besides. the fuzzy data may also come from output measurements judging with humans' partial knowledge or subjectivity or gathered from the manufacturing process with scarce or coarse samples $[15,16,17]$. Therefore, based on the fuzzy sample data to identify whether a manufacturing process exists special causes variation, or is needed to makes certain correction. traditional Shewhart control charts must be expanded so as to possibly carry out the process monitoring in this fuzzy environment [18].

In general, statistical and fuzzy methodologies exist to deal with the categorical data. Early research on statistical methodologies goes back to Duncan [19] who introduced a chisquare control chart for monitoring a multinomial process with categorical data. Later. this type of control chart is discussed further by Marcucci [20] and Nelson [21]. Marcucci [20] introduced a statistical approach for the case, where the proportion of each category is not known before. In the case of fuzzy methodologies, several approaches are proposed. Bradshaw [22] for the first time, used fuzzy sets as a basic for explaining the measurement of conformity of each product unit with the specifications.

In this study, data from related color parameters of grinding process products of a company in NiğdeTurkey are obtained. An application is presented for fuzzy X-R control charts; it's tried to be analyzed whether or not the process is under control by constructing fuzzy control charts using calculated total color differences $(\Delta \mathrm{E})$. In addition, the specifications of the micronized calcite, on a randomly selected sample used in the fuzzy statistical process control work, were then determined by other color parameters such as whiteness index (WI), saturation index $(\mathrm{SI})$, hue angle $(H)$, browning index $(\mathrm{BI})$ and yellowness index (YI) that were calculated and particle size properties of the micronized calcite product were given. In addition, XRD, XRF, FTIR, TGA, DTA analyses were made on the selected ultra-fine grinding sample.

\section{MATERIAL- METHOD}

Conventional ball-mill grinding technology is used to obtain calcite with micronized on the industrial scale. Fine/very fine sizes of calcite products could be produced with the mill running closed circuit by separation of air. Flow diagram of a micronized calcite grinding plant is given in Figure 1. The particle size distribution of the mill feed sample was determined by screening. It is shown in Figure 2. It can be seen that the $\mathrm{d}_{80}$ size is about $1.0 \mathrm{~mm}$ particle size. The products used in statistical color parameters $\left(\mathrm{L}^{*}, \mathrm{a}^{*}, \mathrm{~b}^{*}\right)$ studies are cyclone products. In the total color difference calculations, averages of the five samples values, are used as $\mathrm{L}^{*}=96.77, \mathrm{a}^{*}=0.19, \mathrm{~b}^{*}=1.56$ (Table 1$)$.

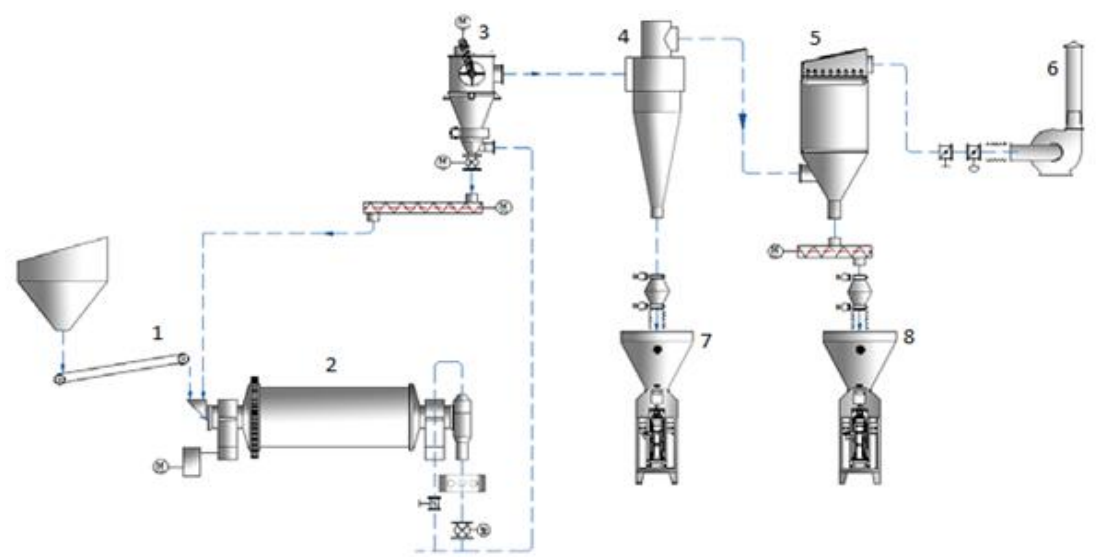

Figure 1. Flow Diagram of a Micronized Calcite Grinding Plant (1-Feed calcite, 2-Ball mill, 3- Separator, 4Cyclone, 5-Filter, 6-Fan, 7-Cyclone product, 8-Filter product) [23]. 
Table 1. Color Parameters Values of the Feed Samples

\begin{tabular}{|c|c|c|c|}
\hline & $\mathrm{L}^{*}$ & $\mathrm{a}^{*}$ & $\mathrm{~b}^{*}$ \\
\hline & 96.74 & 0.12 & 1.45 \\
\hline & 96.63 & 0.20 & 1.51 \\
\hline & 96.73 & 0.30 & 1.82 \\
\hline & 96.91 & 0.20 & 1.50 \\
\hline & 96.85 & 0.14 & 1.51 \\
\hline Avarage & 96.77 & 0.19 & 1.56 \\
\hline
\end{tabular}

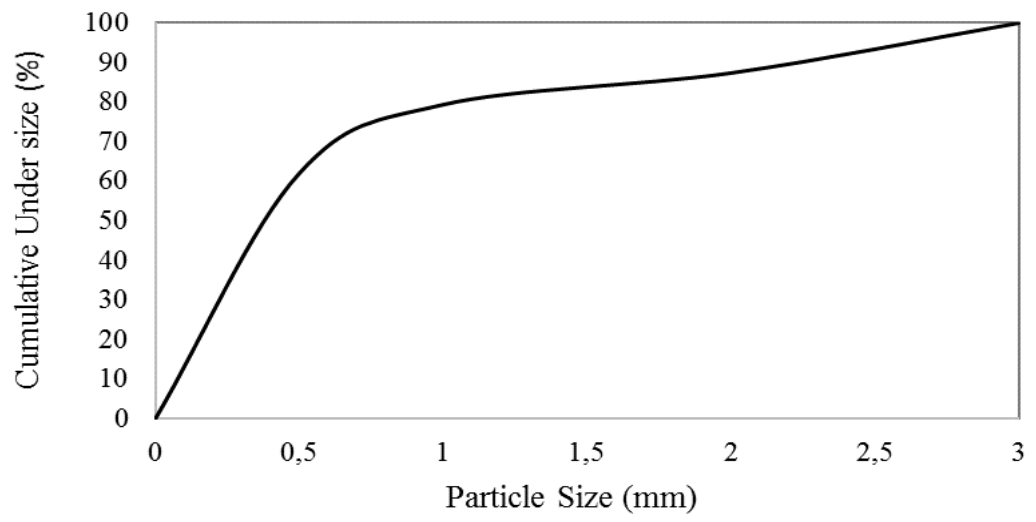

Figure 2. Cumulative Under Size (\%) of Feed Sample

An organization called Commission Internationale del'Eclairage (CIE) determined the standard values that are used worldwide to measure color. The values used by CIE are called L*. $\mathrm{a}^{*}$. and $\mathrm{b}^{*}$, and the color measurement method is called CIELAB. Symbol L* (Lightness) represents the difference between light ("pure white") (where $\left.L^{*}=100\right)$ and dark ("black") (where $L^{*}=0$ ); $a^{*}$ (Redness-Greenness) represents the difference between green $\left(-\mathrm{a}^{*}\right)$ and red $\left(+\mathrm{a}^{*}\right)$; and $\mathrm{b}^{*}$ (Yellowness-Blueness) represents the difference between yellow $\left(+b^{*}\right)$ and blue $\left(-b^{*}\right)[8]$. The colour measurement method is called CIELAB. The CIELAB values are calculated from the red green and blue filters of the colorimeters and are particularly suited to describing near white samples according to the following equations [24]:

$\mathrm{L}^{*}=116\left(\mathrm{Y} / \mathrm{Y}^{\mathrm{n}}\right)^{1 / 3}-16$

$\mathrm{a}^{*}=200\left[\left(\left(\mathrm{X} / \mathrm{X}^{\mathrm{n}}\right)^{1 / 3}-\left(\mathrm{Y} / \mathrm{Y}^{\mathrm{n}}\right)^{1 / 3}\right]\right.$

$b^{*}=200\left[\left(\left(\mathrm{Z} / \mathrm{Z}^{\mathrm{n}}\right)^{1 / 3}-\left(\mathrm{Y} / \mathrm{Y}^{\mathrm{n}}\right)^{1 / 3}\right]\right.$

where $\mathrm{X}$. $\mathrm{Y}$ and $\mathrm{Z}$ are the tristimulus values for the samples arising from the colourimetric system and $\mathrm{X}^{\mathrm{n}}$. $\mathrm{Y}^{\mathrm{n}}$ and $\mathrm{Z}^{\mathrm{n}}$ are those of a surface colour chosen as the nominal white stimulus. Using this system and colour that correspons to a place on the Cylindrical CIELAB color space system was shown in Figure 3.

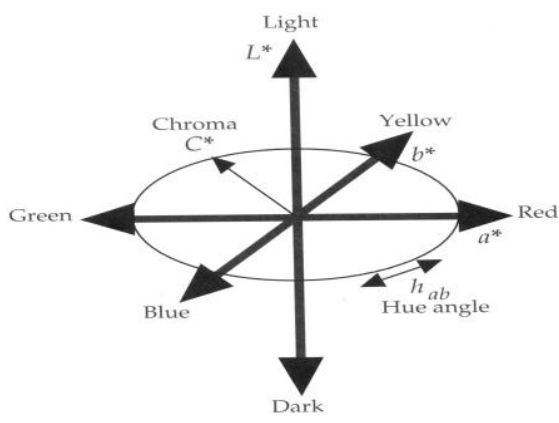

Figure 3. Cylindrical CIELAB Color Space [25] 
Another useful parameter for describing White, which is given in the BS 3900 [26] is delta $\mathrm{E}(\Delta E)$. The total color difference $(\Delta E)$ was calculated using the measurements and Equation 4 . by using $\mathrm{L}^{*}, \mathrm{a}^{*}$ and $\mathrm{b}^{*}$ values $[27,28]$. The color parameters $\left(L^{*}, a^{*}, b^{*}\right)$ of calcite samples were measured using a Datacolor Elrepho SF450X spectrophotometer in the study.

$\Delta E=\left[\left(\mathrm{L}_{0}-\mathrm{L}^{*}\right)^{2}+\left(\mathrm{a}_{0}-\mathrm{a}^{*}\right)^{2}+\left(\mathrm{b}_{0}-\mathrm{b}^{*}\right)^{2}\right]^{0.5}$

where subscript " 0 " refers to the color reading of the feed sample used as the reference, and a larger $\Delta E$ indicates greater color change from the reference sample [24].

The CIELAB, or CIE (1976) $\mathrm{L} * \mathrm{a} * \mathrm{~b} *$ values have a perceptual meaning: $\mathrm{L} *$ is the lightness which relates to the physical intensity of a color, whilst $\mathrm{a}^{*}$ and $\mathrm{b}^{*}$ are coordinates on the red-green and yellow-blue color axes respectively. This scheme is designed such that a constant difference in color, $\Delta \mathrm{E}$, defined by the Euclidean distance. It should give a constant 'perceived' total color difference-regardless of the location in the color space. The smallest perceivable difference for two colored patches contacting one another is approximately $0.5-1.0 \Delta \mathrm{E}$ units [29]. A whiteness index (WI) has been described based on the distance of a color value from a nominal white point, represented in CIELAB color space as $L^{*}=100, a^{*}=0$ and $b^{*}=0$. In spectral terms a white material is one whose reflectance across the visible wave length range is constant and high (i.e. close to $100 \%$ or reflectance factor of 1). Varying shades of gray to black have a constant reflectance with the perfect black having a reflectance of $0 \%$ [30].

The hue angle is traditionally measured starting at the direction corresponding to pure red. The simplest way to derive an expression for this angle is to project the vector $(1 ; 0 ; 0)$ corresponding to red in the RGB (red, green, and blue) space and an arbitrary vector $\mathrm{c}$ onto a plane perpendicular to the achromatic axis, and to calculate the angle between them. For the derivation of an expression for the saturation of an arbitrary color $\mathrm{c}$, we begin by looking at the triangle which contains all the points with the same hue as $\mathrm{c}$. The intersection of this triangle and the iso-brightness surfaces are lines parallel to the line between $\mathrm{c}$ and its brightness value on the achromatic axis $\mathrm{L}(\mathrm{c})=[\mathrm{L}(\mathrm{c}) ; \mathrm{L}(\mathrm{c}) ; \mathrm{L}$ (c)]. Traditionally, the saturation is calculated as the length of the vector from $\mathrm{L}(\mathrm{c})$ to $\mathrm{c}$ divided by the length of the extension of this vector to the surface of the RGB cube. Moreover, it is clear that this definition of the saturation depends intimately on the form of the brightness function chosen (i.e. on the slopes of the iso-brightness lines) [31].

The Hunter $b$ or CIELAB $b^{*}$ coordinate is often used for the characterization of yellowness. Yellowness indices are unduly neglected in the publications reviewed; they report only in a few cases the application of the according to ASTM (2005), where $C_{X}$ and $C_{Z}$ are illuminant- and observer-specific constants, or the formula 6 often referenced [32]. Browning index in the literature may mean one of two things: a simple indicator of a chemical change (often characterized by the optical density at a given wavelength or the ratio of the reflectance at 570 and $650 \mathrm{~nm}$ ) or the color change due to oxidation of a freshly cut fruit or vegetable surface, during storage or drying, or the baking of bread. The simplest (and probably least adequate) indicator of the color change is the $L^{*}$ coordinate (or $100-L^{*}$ or $100 / L^{*}$ ) [33].

Whiteness index (WI), saturation index (SI), hue angle $(H)$, browning index $(\mathrm{BI})$ and yellowness index (YI) were calculated using measured Equation 5, 6, 7, 8 and 9 , respectively by using $L^{*}, a^{*}$ and $b^{*}$ values [33, $34,35]$.

$\mathrm{WI}=100-\left[(100-\mathrm{L} *)^{2}+\mathrm{a} *^{2}+\mathrm{b} *^{2}\right]^{0,5}$

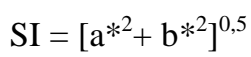

$\mathrm{H}=\arctan (b * / a *)$

$\mathrm{BI}=[100 *(\mathrm{x}-0.31)] / 0.17$

where; $\mathrm{x}=\left(\mathrm{a}^{*}+1.75 \mathrm{xL} *\right) /\left(5.645 \mathrm{xL}^{*}+\mathrm{a}^{*}-3.012 \mathrm{xb}^{*}\right)$

$\mathrm{YI}=142,86 \mathrm{xb} * / \mathrm{L} *$

We now briefly review the development of the equations for constructing the control limits on the $\mathrm{X}$ and $\mathrm{R}$ control charts. In $X$ chart, means of small samples are taken at regular intervals, plotted on a chart and compared against two limits. The limits are known as upper control limit (UCL) and lower control limit (LCL). These limits are defined as below:

$\mathrm{LCL}=\overline{\bar{X}}-\mathrm{A}_{2} * \mathrm{R}$ and

$\mathrm{UCL}=\bar{X}+\mathrm{A}_{2} * \mathrm{R}$

where, $\bar{X}$ is the target mean and factor $\mathrm{A}_{2}$ depends on sample size (Table 2). The process is assumed to be out of control when the sample average falls beyond these limits. 
Table 2. Constants for Control Charts [36]

\begin{tabular}{|c|c|c|c|c|}
\hline Subgroup size (n) & $\mathrm{A}_{2}$ & $\mathrm{D}_{2}$ & $\mathrm{D}_{3}$ & $\mathrm{D}_{4}$ \\
\hline 2 & 1.880 & 1.128 & 0 & 3.267 \\
\hline 3 & 1.023 & 1.693 & 0 & 2.574 \\
\hline 4 & 0.729 & 2.059 & 0 & 2.282 \\
\hline 5 & 0.577 & 2.326 & 0 & 2.114 \\
\hline
\end{tabular}

In these charts, the sample ranges are plotted in order to control the variability of a variable. The centre line of the $\mathrm{R}$ chart is known as average range. The range of a sample is simply the difference between the largest and smallest observation. If $R_{1}, R_{2}, \ldots . R_{\mathrm{k}}$. be the range of k samples, then the average range ( $\mathrm{R}$ bar) is given by: $\bar{R}=\left(\mathrm{R}_{1}+\mathrm{R}_{2}+\mathrm{R}_{3} \ldots \ldots \ldots \ldots \ldots \mathrm{Rn}\right) / \mathrm{k}_{\mathrm{i}}$

The upper and lower control limits of $R$ chart are:

Upper control limit: $\mathrm{UCL}_{\mathrm{R}}=\mathrm{D}_{4} * \bar{R}$

Lower control limit: $\mathrm{LCL}_{\mathrm{R}}=\mathrm{D}_{3} * \bar{R}$

where, factors, $D 2, D_{3}$ and $D_{4}$ depend only on sample size (n) (Table 2) [37]

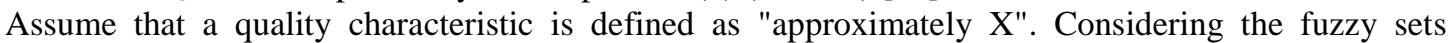
concept, this value can be converted to the triangular fuzzy number (TFN) $\widetilde{X}=\left(\mathrm{X}_{1} ; \mathrm{X}_{2} ; \mathrm{X}_{3}\right)$. After measuring a sample of size $n$ from triangular fuzzy numbers $\left(X_{1 j}, X_{2 j}\right.$. $\left.; X 3 j\right) j=1 ; \ldots \ldots \ldots ; n$, the average of this sample can be calculated by extension principle as follows:

$\tilde{X}=(\overline{X 1}, \overline{X 2}, \overline{X 3})=\left(\frac{\sum_{j=1}^{n} X 1 j}{n}, \frac{\sum_{j=1}^{n} X 2 j}{n}, \frac{\sum_{j=1}^{n} X a j}{n}\right)$

Also considering extension principle. the range of the sample can be calculated by

$\bar{R}=(R 1, R 2, R 3)$

$\bar{R}=(\max X 1 \mathrm{j}, \max X 2 \mathrm{j}, \max X 3 \mathrm{j})-(\min X 1 \mathrm{j}, \min X 2, \min X 3 \mathrm{j})$

$\bar{R}=(\max X 1 \mathrm{j}-\min \mathrm{X} 1 \mathrm{j}, \max \mathrm{X} 2 \mathrm{j}-\min \mathrm{X} 2 \mathrm{j}, \max \mathrm{X} 3 \mathrm{j}-\min \mathrm{X} 3 \mathrm{j})$

where $\left(\max X_{1 j} ; \max X_{2 j} ; \max X_{3 j}\right)$ and $\left(\min X_{1 j} ; \min X_{2 j} ; \min X_{3 j}\right)$ represent the maximum and minimum values of fuzzy measurements, respectively. One method to determine the maximum and minimum values of fuzzy measurements is assign from ranking method [38].

For $\mathrm{m}$ subgroups with size $\mathrm{n}$, the fuzzy grand average and the average range of samples are [39]

$\overline{\bar{X}}=(\overline{\overline{X 1}}, \overline{\overline{X 2}}, \overline{\overline{X 3}})=\frac{\sum_{i=1}^{m} \overline{X I}}{m}, \frac{\sum_{i=1}^{m} X 2 I}{m}, \frac{\sum_{i=1}^{n} X 21}{m}$

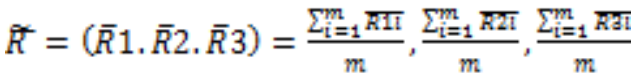

respectively, therefore. the control limits for $\bar{Z}$ control charts are calculated as follows:

$\overline{U C L \bar{X}}=\overline{\bar{X}}+A 2 \overline{\bar{R}}=(\overline{\bar{X}} 1+A 2 \bar{R} 1, \overline{\bar{X}} 2+A 2 \bar{R} 2, \overline{\bar{X}} 3+A 2 \bar{R} 3)$

$\widetilde{C L} \bar{X}=\overline{\bar{X}}=(\overline{\bar{X}} 1, \overline{\bar{X}} 2, \overline{\bar{X}} 3)=(\mathrm{CL}(\overline{\bar{X}}) 1, \mathrm{CL}(\overline{\bar{X}}) 2, \mathrm{CL}(\overline{\bar{X}}) 3)$

$L C L \overline{\bar{X}}=\overline{\bar{X}}-A 2 \overline{\bar{R}}=\left(\overline{\bar{X}} 1-A 2 \bar{R} 1_{x}, \overline{\bar{X}} 2-A 2 \bar{R} 2, \overline{\bar{X}} 3-A 2 \bar{R} 3\right)$

and similarly, for $\tilde{R}$ control chart.

$\overline{U C L R}=\bar{R} D 4=(\mathrm{D} 4 \bar{R} 1, \mathrm{D} 4 \bar{R} 2, D 4 \bar{R} 3)$

$\widetilde{C L} \bar{X}=\bar{R}=(\bar{R} 1, \bar{R} 2, \bar{R} 3)=(\operatorname{CL}(\bar{R}) 1, \mathrm{CL}(\bar{R}) 2, \mathrm{CL}(\bar{R}) 3)$

$L C L R=\bar{R} D 3=(\mathrm{D} 3 \bar{R} 1, \mathrm{D} 3 \bar{R} 2, D 3 \bar{R} 3)$

There have been a number of process capability indices proposed over the years for the purpose of assessing the capability of a process to meet certain specifications. The two most widely used standard PCIs are $\mathrm{Cp}$ and $\mathrm{Cpk}$. The index $\mathrm{Cp}$ which is the first process capability index (PCI) to appear in the literature and called precision index [40] is defined as the ratio of specification width (USL-LSL) over the process spread (6r). The specification width represents customer and/or product requirements. The process variations are represented by the specification width. If the process variation is very large. the Cp value is small and it represents a low process capability. Cp indicates how well the process fits within the two specification limits. It is calculated by using Eq. (22). Cp simply measures the spread of the specifications relative to the six-sigma spread in the process $[38,41]$. The process capability ratio $\mathrm{Cp}$ does not take into account where the process mean is located relative to specifications [38]. Cp focuses on the dispersion of the studied process and does not take into account 
centering the process and thus gives no indication of the actual process performance. Kane (1986) [40] introduced index $\mathrm{Cpk}$ to overcome this problem. The index $\mathrm{Cpk}$ is used to provide an indication of the variability associated with a process. It shows how a process confirms to its specifications. The index is usually used to relate the "natural tolerances (3r)" to the specification limits. Cpk describes how well the process fits within the specification limits. taking into account the location of the process mean. Cpk should be calculated based on Eqs. (27)-(28) [38, 40, 41].

$$
\begin{aligned}
\mathrm{Cp} & =\frac{\text { USL }- \text { LSL }}{6 \sigma} \\
\mathrm{Cpk} & =\min \left[\frac{\text { USL }-\mathrm{p}}{3 \sigma} \cdot \frac{\mathrm{\mu}-\text { USL }}{3 \sigma}\right]
\end{aligned}
$$

where $\mu$ denotes the process mean. $\mathrm{Cpu}, 1$ indicates. in addition. how well the distribution is centred about the nominal (target) value, a property that can better reveal the relationship between the mean and objective values.

Assume that specification limits (SLs) and measurements of the considered quality characteristic are defined by linguistic variables such as "approximately" or "around". Triangular fuzzy numbers (TFNs) are more suitable for this case. SLs can be defined as follows:

$\widetilde{V S L}=T F N(u 1, u 2, u 3)$

$\overparen{L S L}=$ TFN $(11, l 2, I 3)$

Also fuzzy process mean $\tilde{\mu}$ and standard deviation $\tilde{\sigma}$ can be calculated as follows [42]:

$\tilde{\mu}=\overline{\bar{X}}=\mathrm{TFN}(\mu 1, \mu 2, \mu 3)$

$\tilde{\sigma}=\frac{\mathbb{R}}{d 2}=\left(\frac{\mathbb{R} 1}{d 2}, \frac{\mathbb{R} 2}{d 2}, \frac{\mathbb{R} 1}{d 2}, \frac{\mathrm{Fa}}{d 2}\right)=\mathrm{TFN}(\mathrm{s} 1, \mathrm{~s} 2, \mathrm{~s} 3)$

Based on these definitions. fuzzy process capability indices can be calculated as follows:

$$
\begin{aligned}
& C_{p}=\frac{\overline{W S L}-[S T}{6 \sigma}=\operatorname{TFN}\left(\frac{w 1-11}{651}, \frac{w 2-12}{6 S 2}, \frac{w a-19}{65 a}\right) \\
& C_{p u}=\frac{\overline{W S 1}-\mu}{\mathrm{a} \sigma}=\mathrm{TFN}\left(\frac{\mathrm{u1}-\mu 1}{\mathrm{as1}}, \frac{\mathrm{w2}-\mu 2}{\mathrm{as2}}, \frac{\mathrm{ua}-\mu \mathrm{a}}{\mathrm{asa}}\right) \\
& C_{p l}=\frac{\mu-[S L}{\mathrm{a} \sigma}=\mathrm{TFN}\left(\frac{\mathrm{p} 1-\mathrm{i} 1}{\mathrm{a} 1}, \frac{\mathrm{\mu} 2-\mathrm{i} 2}{\mathrm{a} 2}, \frac{\mathrm{pa}-\mathrm{ia}}{\mathrm{a} a \mathrm{a}}\right)
\end{aligned}
$$

The value of index Cp gives us an opinion about process' performance. For example if it is greater than 1.33 which corresponds to 63 nonconforming parts per million (ppm) for a centered process. we conclude that process performance is satisfactory. The six quality conditions and the corresponding Cpvalues are summarized in Table 3 [43].

Table 3. Quality Conditions and Cp Values [43]

\begin{tabular}{|c|c|}
\hline Quality conditions & $\mathrm{Cp}$ values \\
\hline Super excellent & $2.00 \leq \mathrm{Cp}$ \\
\hline Excellent & $1.67 \mathrm{Cp} \leq 2.00$ \\
\hline Satisfactory & $1.33 \mathrm{Cp} \leq 1.67$ \\
\hline Capable & $1.00 \mathrm{Cp} \leq 1.33$ \\
\hline Inadequate & $0.67 \mathrm{Cp} \leq 1.00$ \\
\hline Poor & $\mathrm{Cp}<0.67$ \\
\hline
\end{tabular}

The mean particle size and width of PSD of the final ultra-fine calcite products were determined. There are several evaluation methods that have been used to represent the width of the PSD of ground product. The cumulative weight passing particle sizes $d_{20}$ and $d_{80}[44,45]$ are used to evaluate the width of the PSD in mineral processing, and the particle size ratio of $\mathrm{d}_{80} / \mathrm{d}_{20}$ is often calculated for the PSD width. The particle sizes $\mathrm{d}_{10}, \mathrm{~d}_{50}$, and $\mathrm{d}_{90}$ are used for the evaluation of the grinding characteristic of solid materials $[46,47,48]$. The particle size ratio of $d_{90} / d_{10}$ is more useful for representing the PSD width because the size ratio of $d_{90} / d_{10}$ has a wider range comparison than the ratio $\mathrm{d}_{80} / \mathrm{d}_{20}$. The size ratio $\left(\mathrm{d}_{90}-\mathrm{d}_{10}\right) / \mathrm{d}_{50}$ ("span value") also can be used in addition to the ratios $\mathrm{d}_{80} / \mathrm{d}_{20}$ and $\mathrm{d}_{90} / \mathrm{d}_{10}[49,50]$. A decrease in these particle size ratios means a narrower PSD. 
On the other hand, steepness ratio can be also defined by the "steepness factor" (SF). The SF can be calculated from the PSD curve of the powder using the following equation:

$\mathrm{SF}=\mathrm{d}_{50} / \mathrm{d}_{20}$

A curve with the greater than 2 is described as "broad" and those with the factor of less than 2 as "narrow" or "steep", [51].

In this study, the particle size distribution and values of whiteness color parameters $\left(\mathrm{L}^{*}, \mathrm{a}^{*}, \mathrm{~b}^{*}\right)$ were determined using Mastersizer 2000 (Malvern) and Elrepho 450x (Datacolor) in the laboratory of Mikrokal Co. Nigde-Turkey. Other analyses were performed at Bayburt University. XRD analysis was made between $2-70^{\circ}$ by $\mathrm{Cu}$ X-ray tube D8 DISCOVER device. TG-DTA and SEM analyzes were performed by using Perkin Elmer STA 8000 and Nova Nano SEM 450 instruments, respectively. The vibration modes of functional groups of the compound were determined by Fourier transforms infrared (FTIR) analysis. The FTIR spectra were measured in the range of $450-4000 \mathrm{~cm}-1$ by the Perkin Elmer Spectrum Two.

\section{RESULTS}

In this study, fuzzy $\mathrm{X}$ and $\mathrm{R}$ control charts for monitoring the process average and variability based on the fuzzy sample data were given as an example. The appearance of the display seen through total color difference is of great importance for micronized calcite users. For this reason, companies evaluate the amount of total color difference values from feed and ultra-fine calcite products. Color parameters of ground calcite samples are measured with a few grams of sample, obtained from tons of material. Therefore, it seems to be the right approach to use fuzzy statistical methods. At the present time, fuzzy statistical process control methods based upon the product quality data have been the standard approach to process monitoring. In order to analyze the variation in color parameters such as $\mathrm{L}^{*}, \mathrm{a}^{*}$ and $\mathrm{b}^{*}$ (measured using Datacolor Elrepho 450x Datacolor) of the ground calcites delivered to the conventional ball-mill with control charts, data from 20 days have been gathered. Data arranged as $m=20$ (number of sample) and $n=4$ (size of sample) are given in the Figure 4, 5 and 6. Calculated values of total color differences $(\Delta E)$ using feed and ground samples are given in Table 4.

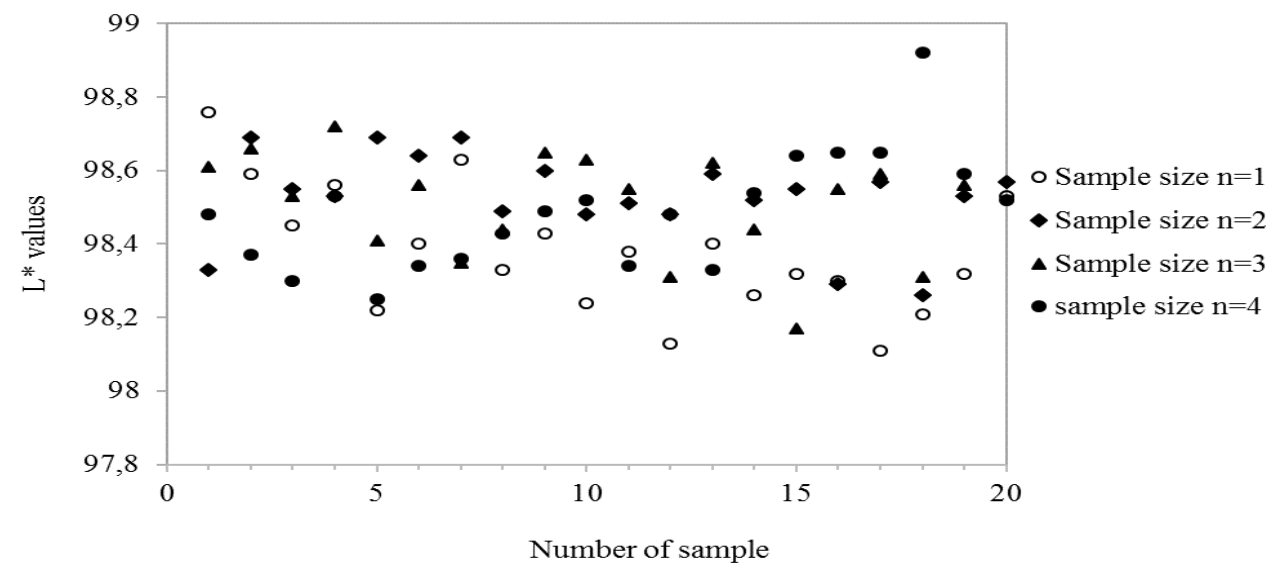

Figure 4. Case Study Data for L* Values

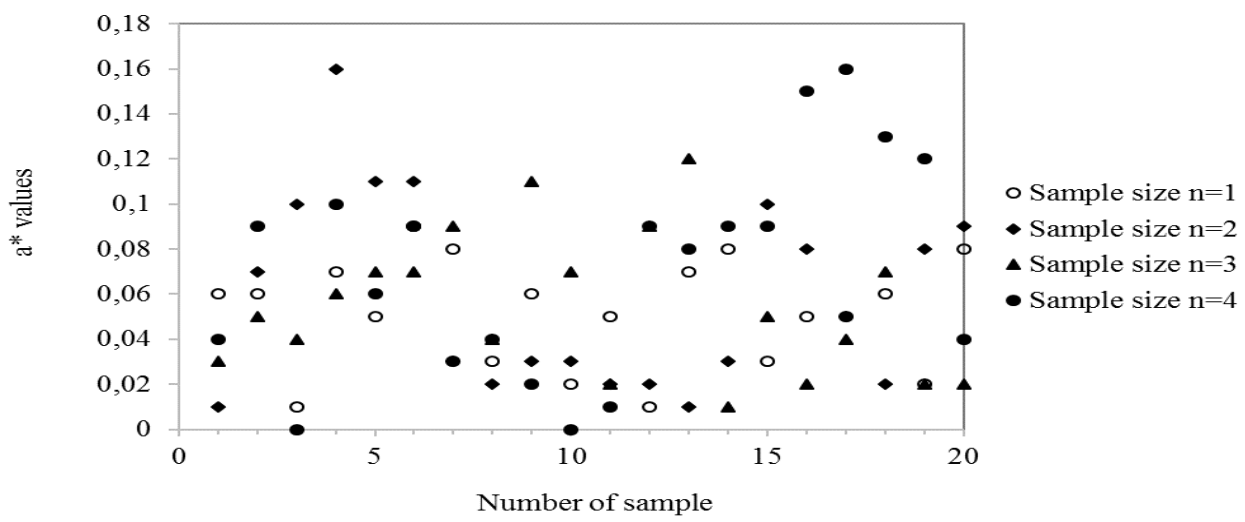

Figure 5. Case Study Data for a* Values 


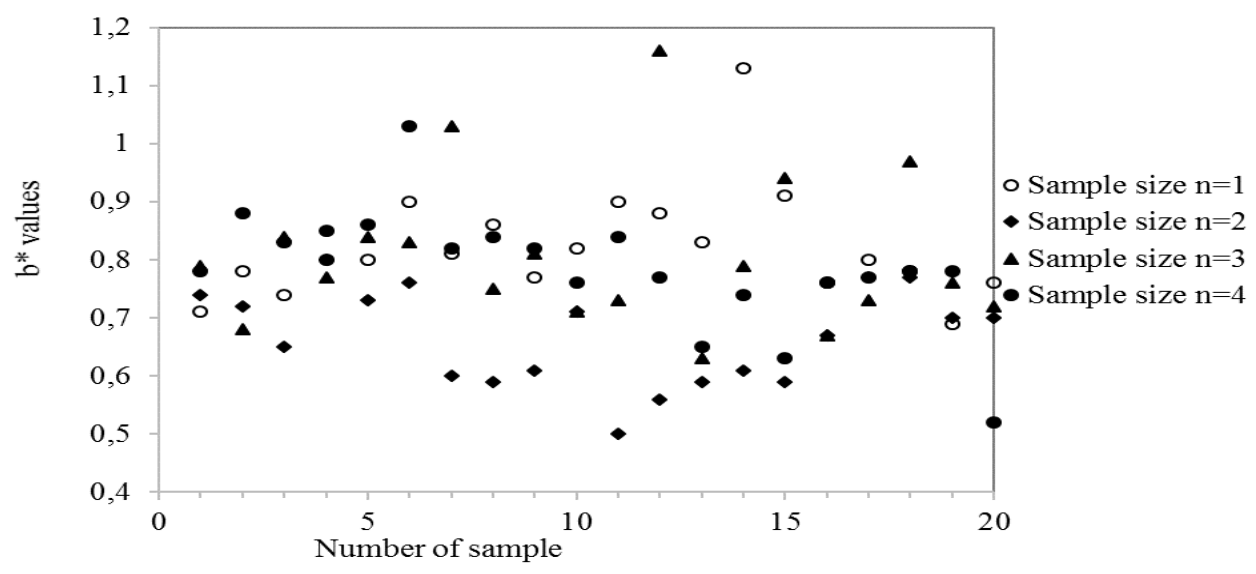

Figure 6. Case Study Data for $b^{*}$ Values

Table 4. Calculated Values of Total Color Differences $(\Delta \mathrm{E})$

\begin{tabular}{|c|c|c|c|c|}
\hline Sample & 1 & 2 & 3 & 4 \\
\hline 1 & 2.165 & 1.769 & 1.999 & 1.883 \\
\hline 2 & 1.982 & 2.097 & 2.087 & 1.739 \\
\hline 3 & 1.876 & 1.999 & 1.905 & 1.703 \\
\hline 4 & 1.946 & 1.915 & 1.957 & 1.897 \\
\hline 5 & 1.641 & 2.095 & 1.793 & 1.640 \\
\hline 6 & 1.759 & 2.033 & 1.934 & 1.658 \\
\hline 7 & 2.006 & 2.150 & 1.667 & 1.759 \\
\hline 8 & 1.715 & 1.979 & 1.860 & 1.813 \\
\hline 9 & 1.840 & 2.066 & 2.023 & 1.878 \\
\hline 10 & 1.652 & 1.914 & 2.046 & 1.931 \\
\hline 11 & 1.743 & 2.042 & 1.969 & 1.734 \\
\hline 12 & 1.529 & 1.806 & 1.592 & 1.884 \\
\hline 13 & 1.788 & 2.068 & 2.069 & 1.807 \\
\hline 14 & 1.552 & 1.995 & 1.845 & 1.951 \\
\hline 15 & 1.686 & 2.027 & 1.535 & 2.088 \\
\hline 16 & 1.730 & 1.762 & 1.995 & 2.041 \\
\hline 17 & 1.544 & 1.968 & 2.003 & 2.037 \\
\hline 18 & 1.640 & 1.693 & 1.651 & 2.285 \\
\hline 19 & 1.783 & 1.959 & 1.966 & 1.979 \\
\hline 20 & 1.934 & 1.995 & 1.760 & 2.039 \\
\hline
\end{tabular}

Firstly, a normal distribution test was made with SPSS program. The results showed that the process is said to be normally distributed because the value obtained, 0.457 , is larger than $\alpha=0.05$ (\% 95 reliability level). Therefore, it can be said that the process is normal distribution. In this paper, $\bar{X}$-R control charts were redesigned when the quality characteristics are defined as fuzzy measurements. While the $\tilde{X}-\tilde{R}$ charts are designed, one case in which measurements represent triangular fuzzy numbers (TFNs) was taken into account. The calculations in Table 5 have been determined as approximate values. Then, the process is checked to determine whether or not it is in statistical control. The results are shown in Table 6. Using Eqs. 21-26, UCL $\mathrm{L}_{\mathrm{X}}$ $\mathrm{CL}_{\mathrm{X}}, \mathrm{LCL}_{\mathrm{X}}$ and $\mathrm{UCL}_{\mathrm{R}}, \mathrm{CL}_{\mathrm{R}}, \mathrm{LCL}_{\mathrm{X}}$ are calculated as Table 7. 
Table 5. Total Color Difference as Triangular Fuzzy Numbers (TFNs)

\begin{tabular}{|l|l|c|c|c|}
\hline & $\mathrm{X} 1$ & $\mathrm{X} 2$ & $\mathrm{X} 3$ & $\mathrm{X} 4$ \\
\hline 1 & $2.160,2.165,2.170$ & $1.764,1.769,1.774$ & $1.994,1.999,2.004$ & $1.878,1.883,1.888$ \\
\hline 2 & $1.977,1.982,1.987$ & $2.092,2.097,2.102$ & $2.082,2.087,2.092$ & $1.734,1.739,1.744$ \\
\hline 3 & $1.871,1.876,1.881$ & $1.994,1.999,2.004$ & $1.900,1.905,1.910$ & $1.698,1.703,1.708$ \\
\hline 4 & $1.941,1.946,1.951$ & $1.910,1.915,1.920$ & $1.952,1.957,1.962$ & $1.892,1.897,1.902$ \\
\hline 5 & $1.636,1.641,1.646$ & $2.090,2.095,2.100$ & $1.788,1.793,1.798$ & $1.635,1.640,1.645$ \\
\hline 6 & $1.754,1.759,1.764$ & $2.028,2.033,2.038$ & $1.929,1.934,1.939$ & $1.653,1.658,1.663$ \\
\hline 7 & $2.001,2.006,2.011$ & $2.145,2.150,2.155$ & $1.662,1.667,1.672$ & $1.754,1.759,1.764$ \\
\hline 8 & $1.710,1.715,1.720$ & $1.974,1.979,1.984$ & $1.855,1.860,1.865$ & $1.808,1.813,1.818$ \\
\hline 9 & $1.715,1.715,1.715$ & $2.061,2.066,2.071$ & $2.018,2.023,2.028$ & $1.873,1.878,1.883$ \\
\hline 10 & $1.647,1.652,1.657$ & $1.909,1.914,1.919$ & $2.041,2.046,2.051$ & $1.926,1.931,1.936$ \\
\hline 11 & $1.738,1.743,1.748$ & $2.037,2.042,2.047$ & $1.964,1.969,1.974$ & $1.729,1.734,1.739$ \\
\hline 12 & $1.524,1.529,1.534$ & $1.801,1.806,1.811$ & $1.587,1.592,1.597$ & $1.879,1.884,1.889$ \\
\hline 13 & $1.783,1.788,1.793$ & $2.063,2.068,2.073$ & $2.064,2.069,2.074$ & $1.802,1.807,1.812$ \\
\hline 14 & $1.547,1.552,1.557$ & $1.990,1.995,2.000$ & $1.840,1.845,1.850$ & $1.946,1.951,1.956$ \\
\hline 15 & $1.681,1.686,1.691$ & $2.022,2.027,2.032$ & $1.530,1.535,1.540$ & $2.083,2.088,2.093$ \\
\hline 16 & $1.725,1.730,1.735$ & $1.757,1.762,1.767$ & $1.990,1.995,2.000$ & $2.036,2.041,2.046$ \\
\hline 17 & $1.539,1.544,1.549$ & $1.963,1.968,1.973$ & $1.998,2.003,2.008$ & $2.032,2.037,2.042$ \\
\hline 18 & $1.635,1.640,1.645$ & $1.688,1.693,1.698$ & $1.646,1.651,1.656$ & $2.280,2.285,2.290$ \\
\hline 19 & $1.778,1.783,1.788$ & $1.954,1.959,1.964$ & $1.961,1.966,1.971$ & $1.974,1.979,1.984$ \\
\hline 20 & $1.929,1.934,1.939$ & $1.990,1.995,2.000$ & $1.755,1.760,1.765$ & $2.034,2.039,2.044$ \\
\hline & & & & \\
\hline
\end{tabular}

Table 6. Average and Range Values with Control Results

\begin{tabular}{|l|l|l|l|l|}
\hline & \multicolumn{1}{|c|}{$\mathrm{X}$} & Decision & $\mathrm{R}$ & Decision \\
\hline 1 & $1.949,1.954,1.959$ & In control & $0.396,0.396,0.396$ & In control \\
\hline 2 & $1.971,1.976,1.981$ & In control & $0.358,0.358,0.358$ & In control \\
\hline 3 & $1.865,1.870,1.875$ & In control & $0.296,0.296,0.296$ & In control \\
\hline 4 & $1.923,1.928,1.933$ & In control & $0.060,0.060,0.070$ & In control \\
\hline 5 & $1.787,1.792,1.797$ & In control & $0.455,0.455,0.455$ & In control \\
\hline 6 & $1.841,1.792,1.851$ & In control & $0.375,0.375,0.375$ & In control \\
\hline 7 & $1.890,1.895,1.900$ & In control & $0.483,0.483,0.483$ & In control \\
\hline 8 & $1.836,1.841,1.846$ & In control & $0.264,0.264,0.264$ & In control \\
\hline 9 & $1.916,1.920,1.924$ & In control & $0.346,0.351,0.356$ & In control \\
\hline 10 & $1.880,1.885,1.890$ & In control & $0.394,0.394,0.394$ & In control \\
\hline 11 & $1.867,1.872,1.877$ & In control & $0.308,0.308,0.308$ & In control \\
\hline 12 & $1.697,1.702,1.707$ & In control & $0.277,0.313,0.355$ & In control \\
\hline 13 & $1.928,1.933,1.938$ & In control & $0.281,0.281,0.281$ & In control \\
\hline 14 & $1.830,1.835,1.840$ & In control & $0.443,0.443,0.443$ & In control \\
\hline 15 & $1.829,1.834,1.839$ & In control & $0.402,0.402,0.553$ & In control \\
\hline 16 & $1.877,1.882,1.887$ & In control & $0.311,0.311,0.311$ & In control \\
\hline 17 & $1.883,1.888,1.893$ & In control & $0.493,0.493,0.493$ & In control \\
\hline 18 & $1.812,1.817,1.822$ & In control & $0.635,0.645,0.645$ & In control \\
\hline 19 & $1.916,1.921,1.926$ & In control & $0.196,0.196,0.196$ & In control \\
\hline 20 & $1.927,1.932,1.937$ & In control & $0.279,0.279,0.279$ & In control \\
\hline Avarage & $1.871,1.876,1.881$ & & $0.353,0.355,0.366$ & \\
\hline & & & & \\
\hline
\end{tabular}


Table 7. $\mathrm{UCL}_{\mathrm{X}}, \mathrm{CL}_{\mathrm{X}}, \mathrm{LCL}_{\mathrm{X}}$ and $\mathrm{UCL}_{\mathrm{R}}, \mathrm{CL}_{\mathrm{R}}, \mathrm{LCL}_{\mathrm{X}}$ Values

\begin{tabular}{|c|c|c|c|c|}
\hline \multirow{3}{*}{$\mathrm{X}$} & $\mathrm{UCL}_{\mathrm{X}}$ & 2.12 & 2.13 & 2.15 \\
\cline { 2 - 5 } & $\mathrm{CL}_{\mathrm{X}}$ & 1.87 & 1.88 & 1.88 \\
\cline { 2 - 5 } & $\mathrm{LCL}_{\mathrm{X}}$ & 1.62 & 1.62 & 1.62 \\
\hline \multirow{3}{*}{$\mathrm{R}$} & $\mathrm{UCL}_{\mathrm{R}}$ & 0.79 & 0.8 & 0.82 \\
\cline { 2 - 5 } & $\mathrm{CL}_{\mathrm{R}}$ & 0.35 & 0.36 & 0.37 \\
\cline { 2 - 5 } & $\mathrm{LCL}_{\mathrm{R}}$ & 0 & 0 & 0 \\
\hline
\end{tabular}

The TFNs of USL and LSL as expected values for calculations indexes were obtained from the management of the plant. Fuzzy process capability indices (PCIs) are determined for the inside total color difference. The measurements in Table 8 are shown as approximate values. Then, the process is checked to determine whether or not it is in statistical control. According to Table 8 and $\mu, \sigma, \mathrm{Cp}, \mathrm{Cpu}$ and $\mathrm{Cpl}$ were obtained by using Equation 26-30 (Table 9). The index Cp, Cpu and $\mathrm{Cpl}$ were determined as 3.889-3.866$3.1795,6.084,6.039,5.499$ and $1.695,1.694,1.653$, respectively. The parameters values after performing the few iterations of data collection were greater than 1.33 and it was determined that the plant was adequate for produce coated calcite.

Table 8. Fuzzy Capability Indexes Total Color Difference of Plant

\begin{tabular}{|c|c|}
\hline & $\Delta \mathrm{E}$ \\
\hline USL & $4.995-5.000-5.005$ \\
\hline LSL & $0.995-1.000-1.005$ \\
\hline
\end{tabular}

Table 9. Values of $\mu, \sigma, \mathrm{Cp}, \mathrm{Cpu}$ and $\mathrm{Cpl}$ Parameters

\begin{tabular}{|c|c|}
\hline Parameters & Values \\
\hline$\mu$ & $1.872,1.876,1.881$ \\
\hline$\sigma$ & $0.171,0.172,0.178$ \\
\hline $\mathrm{Cp}$ & $3.889,3.867,3.179$ \\
\hline $\mathrm{Cpu}$ & $6.084,6.039,5.499$ \\
\hline $\mathrm{Cpl}$ & $1.695,1.694,1.653$ \\
\hline
\end{tabular}

\section{Other Color Properties of Randomly Selected Micronized Calcite Product}

Other color parameters such as whiteness index (WI), saturation index (SI), hue angle $(H)$, browning index (BI) and yellowness index (YI) were calculated in the chapter. The color parameters of the randomly selected sample, because the process is under control, are $\mathrm{L}^{*}=98.48, \mathrm{a}^{*}=0.03, \mathrm{~b}^{*}=0.71$. Total color difference $(\Delta E)$, which is a combination of parameters $L^{*}, a^{*}$ and $b^{*}$ values, is a colorimetric parameter extensively used in the micronized calcite products to characterize the variation of colors depending on processing conditions. An increase in $\Delta E$ was observed (Table 10) with grinding operation from 0 to 1.91. The smallest perceivable difference for two colored patches contacting one another is approximately $0.5-1.0 \Delta \mathrm{E}$ units. Therefore, it can be indicated that a very large color change occurs between products. Experimental results are shown in Table 4 that indicates significant increase from 96.09 to 98.32 for WI with grinding process. As seen in the same table, the saturation index (SI) decreased from 1.57 to 0.71 . In addition, on hue angle $(\mathrm{H})$, values increased important ratio from 82.97 to 97.31 . Besides these, significant reductions were obtained in BI and YI color parameters with calcite ore grinding. 
Table 10. Other Color Parameters Values

\begin{tabular}{|c|c|c|}
\hline Parameters & Feed calcite & Micronized calcite \\
\hline$\Delta \mathrm{E}$ & 0 & 1.91 \\
\hline WI & 96.09 & 08.32 \\
\hline SI & 1.57 & 97.31 \\
\hline H & 82.97 & 0.73 \\
\hline BI & 1.76 & 1.03 \\
\hline YI & 1.73 & \\
\hline
\end{tabular}

\section{Particle Size Properties of Randomly Selected Micronized Calcite Product}

In this study, cumulative under size $(\%)$ of the product, randomly selected sample, are given in Figure 7. The product has $\mathrm{d}_{10}=0.74, \mathrm{~d}_{50}=2.84 \mu \mathrm{m}$ and $\mathrm{d}_{90}=7.40 \mu \mathrm{m}$ particle sizes. The size of calcite ore $\left(\mathrm{d}_{50}=1 \mathrm{~mm}\right)$ has been reduced to ultra-fine dimensions $\left(\mathrm{d}_{50}=2.84 \mu \mathrm{m}\right)$ after grinding and separation processes. Table 11 shows some specific particle size, SF, and span values of feed material and final products. The mean particle size of the feed powder as received was approximately $2.84 \mu \mathrm{m}$ and the steepness ratio was reduced from 3.00 to 2.69. A curve with greater than 2 is described as "broad," and the one with the factor of less than 2 as "narrow" and "steep." Expect for one, all of them have smaller values than 2; namely, micronized talc products show broad properties according to SF. In addition, the results of $\mathrm{d}_{90} / \mathrm{d}_{10}, \mathrm{~d}_{80} / \mathrm{d}_{20}$ and $\left.\mathrm{d}_{90}-\mathrm{d}_{10}\right) / \mathrm{d}_{50}$, PSD width calculations showed that their values decreased with grinding process.

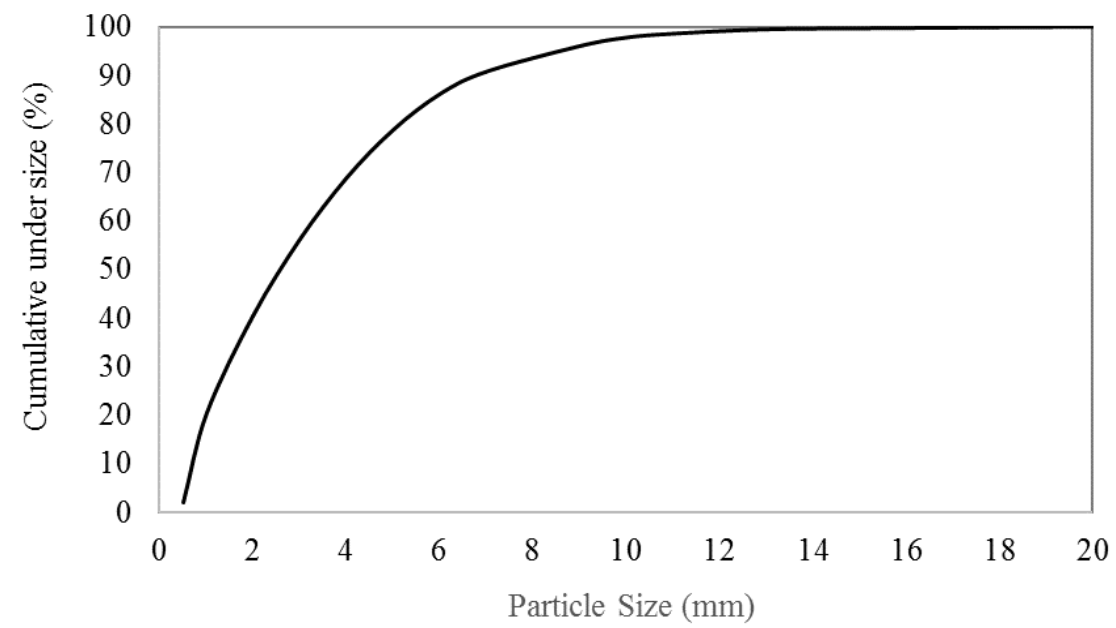

Figure 7. Cumulative Under Size (\%) of Randomly Selected Micronized Calcite Product

Table 11. Variation of Some of the Parameters of The Particle Size Distribution with Grinding Time for the Final Product

\begin{tabular}{|c|c|c|c|c|}
\hline Meterial & SF & \multicolumn{3}{|c|}{ Width of PSD $\left(\mathrm{W}_{\text {PSD }}\right)$} \\
& $\left(\mathrm{d}_{50} / \mathrm{d}_{20}\right)$ & $\mathrm{d}_{90} / \mathrm{d}_{10}$ & $\mathrm{~d}_{80} / \mathrm{d}_{20}$ & Span $\left.\left[\left(\mathrm{d}_{90}-\mathrm{d}_{10}\right) / \mathrm{d}_{50}\right)\right]$ \\
\hline Feed & 3.00 & 22.50 & 8.00 & 5.73 \\
\hline Micronized & 2.69 & 10.0 & 5.44 & 2.35 \\
\hline
\end{tabular}




\section{Some analyses of Randomly Selected Micronized Calcite Product}

Chemical properties of micronized calcite sample are reported in Table 12. The analysis indicated that the ore was composed of $99.6 \% \mathrm{CaCaO}_{3}$. X-ray diffraction analysis verified that calcite was the sole mineral in the ore (Figure 8).

Table 12. Chemical Properties of Micronized Calcite Sample [52]

\begin{tabular}{|c|c|}
\hline Property & $\%$ \\
\hline $\mathrm{CaCO}_{3}$ & 99.60 \\
\hline $\mathrm{SiO}_{2}$ & 0.01 \\
\hline $\mathrm{Al}_{2} \mathrm{O}_{3}$ & 0.02 \\
\hline $\mathrm{FeO}_{2}$ & 0.01 \\
\hline $\mathrm{MgO}$ & 0.20 \\
\hline Others & 0.16 \\
\hline Total & 100 \\
\hline
\end{tabular}

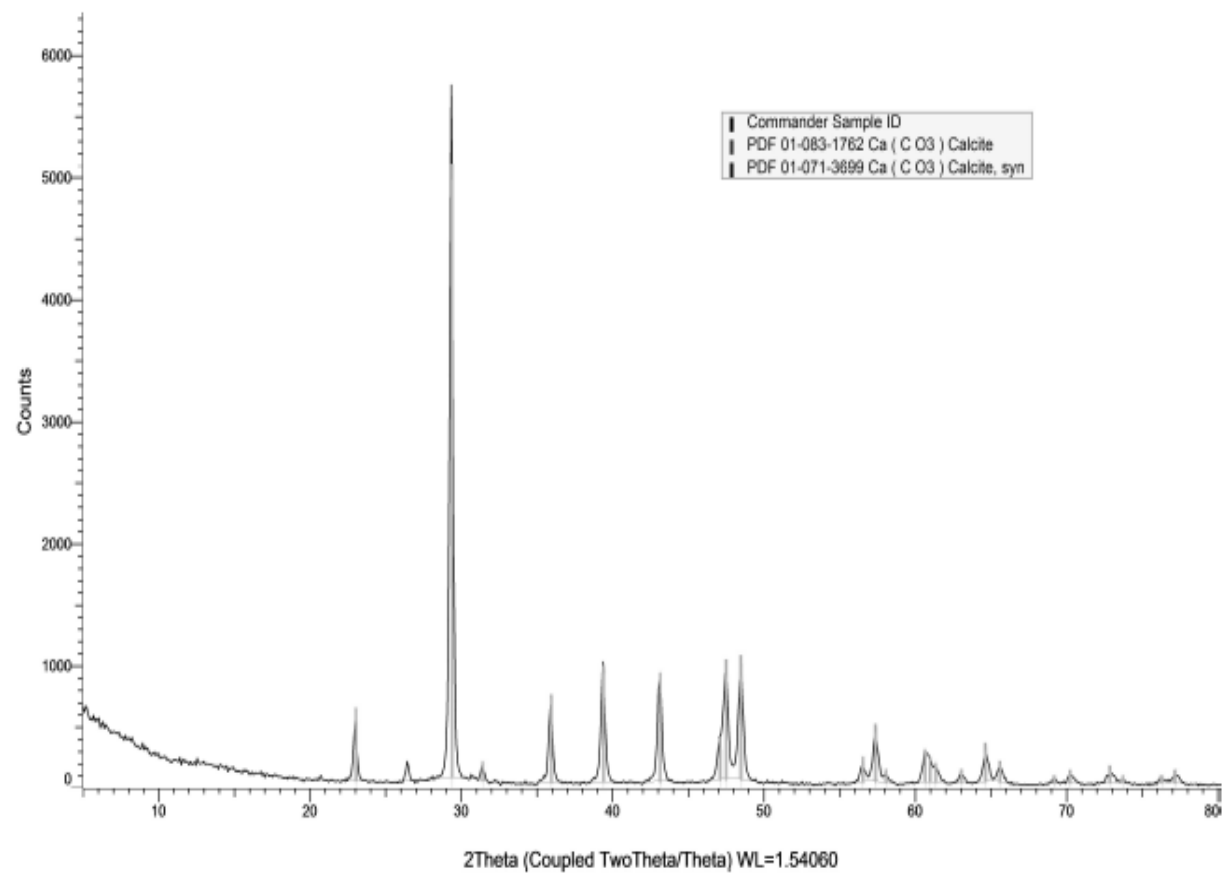

Figure 8. X-ray Diffraction Analysis of Randomly Selected Micronized Calcite Product

For calcite, two main steps are usually visible in the thermal curves in the temperature range of 25$600^{\circ} \mathrm{C}$. The third part starts at approximately $580^{\circ} \mathrm{C}$ and corresponds to the decomposition of calcite [53]. DTA and TG results on micronized calcite samples are presented in Figure 9. It can be clearly seen that there is no exothermic reaction in the DTA result of the micronized calcite sample. No weight loss is observed in the micronized calcite up to approximately $600{ }^{\circ} \mathrm{C}$ in the TGA analysis. As a further characterization method, FTIR spectral analysis was carried out on the micronized samples. Cifrulak (1970) [54] showed that the vibration modes of calcium carbonate result in three active IR bands, $714 \mathrm{~cm}^{-1}$ (v4-in-plane bend), $879 \mathrm{~cm}^{-1}$ (v2-out-ofplane bend) and $1432 \mathrm{~cm}^{-1}$ (v3-antisymmetric stretching), and one inactive band at $1097 \mathrm{~cm}^{-1}$ (v1-symmetric stretching). FTIR analyses of micronized calcite is shown in Figure 10. It can be seen that the IR bands are overlapping each other. The bands at $712 \mathrm{~cm}^{-1}, 873 \mathrm{~cm}^{-1}$ and $1406 \mathrm{~cm}^{-1}$ are diagnostic for the calcite sample. 


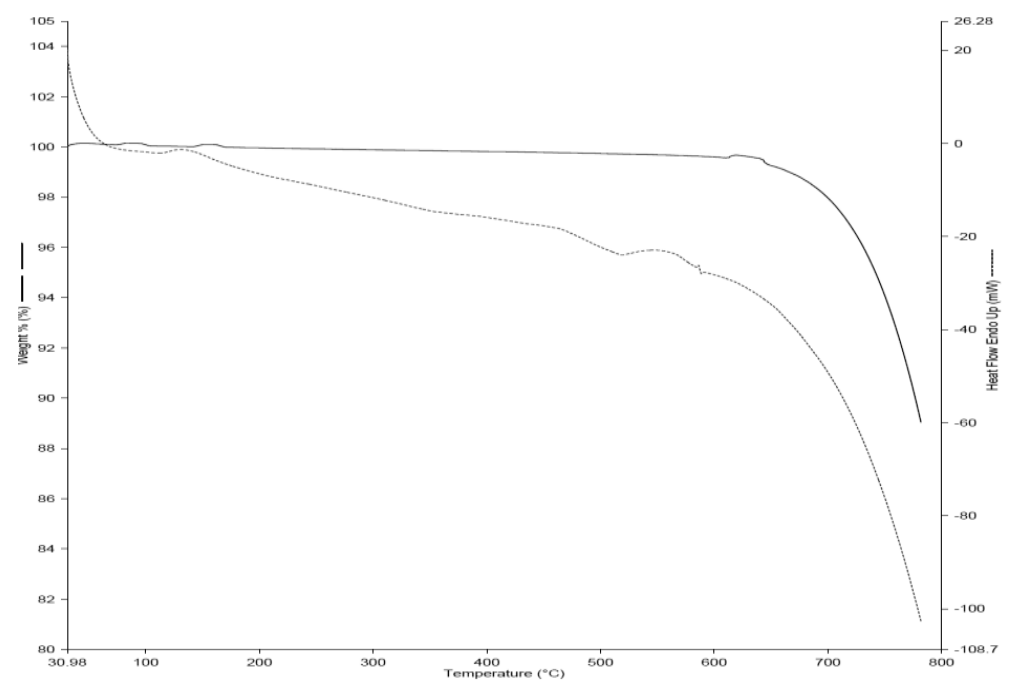

Figure 9. TG and DTA Analysis of Randomly Selected Micronized Calcite Product

Scanning Electron Microscopy (SEM), also known as SEM analysis or SEM microscopy, is used very effectively in microanalysis and failure analysis of solid inorganic materials. Scanning electron microscopy is performed at high magnifications, generates high-resolution images and precisely measures very small features and objects [55]. Figure 11 shows scanning electron microscopy (SEM) images of micronized calcite. It can be seen that the surface of calcite after grinding appears smooth and uniform.

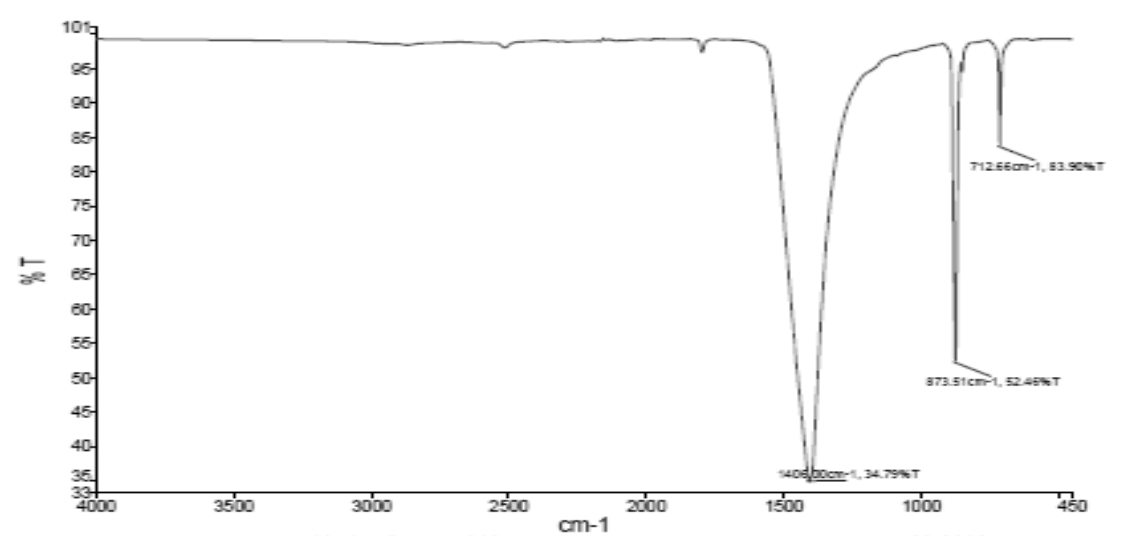

Figure 10. FTIR Analysis of Randomly Selected Micronized Calcite Product

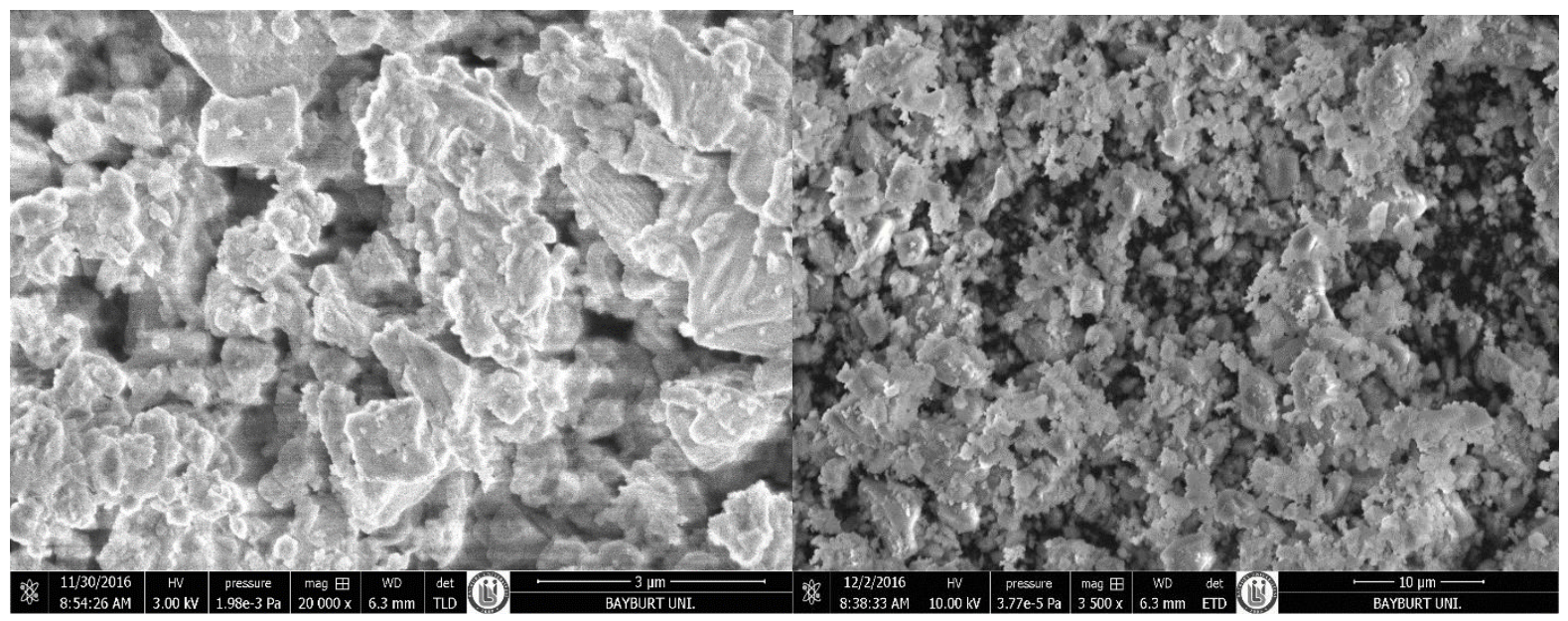

Figure 11. SEM Analysis of Randomly Selected Micronized Calcite Product 


\section{CONCLUSION}

The results acquired from this study which aims the fuzzy process controlling of the relevance of a calcite grinding plant using color difference parameter $(\Delta \mathrm{E})$ of a commercial foundry are summarized below;

i) The process variations have to be controlled using fuzzy statistical process control and process capability index that is one of the important aspects in any production line. $X$-R control charts created with color difference were observed to be in control. In addition, the calculated $\mathrm{Cp}$ values such as 3.889-3.8673.179, are greater than 1.33. Meanwhile, the Cpru and Cprl values are greater than 1.33. Therefore, it can be said that the process is adequate.

ii) Total color difference $(\Delta E)$, which is a combination of parameters $L^{*}, a^{*}$ and $b^{*}$ values, is a colorimetric parameter extensively used in the micronized calcite products to characterize the variation of colors depending on processing conditions. An increase in $\Delta E$ was observed with the grinding operation from 0 to 1.91. Experimental results are shown which indicate significant increase from 96.09 to 98.32 for WI with grinding process. As seen in the same table, the saturation index (SI) decreased from 1.57 to 0.71 . In addition, on hue angle $(\mathrm{H})$, values increased important ratio from 82.97 to 97.31 . Besides these, significant reductions were obtained in BI and YI color parameters with calcite ore grinding.

iii) In this study, cumulative under size (\%) of the product, randomly selected sample has $\mathrm{d}_{10}=0.74, \mathrm{~d}_{50}=2.84 \mu \mathrm{m}$ and $\mathrm{d}_{90}=7.40 \mu \mathrm{m}$ particle sizes. The mean particle size of the feed powder as received was approximately $2.84 \mu \mathrm{m}$ and the steepness ratio was reduced from 3.00 to 2.69 . A curve with greater than 2 is described as "broad," and the one with the factor of less than 2 as "narrow" and "steep." Expect for one, all of them have smaller values than 2; namely, micronized talc products show broad properties according to SF. In addition, the results of $d_{90} / d_{10}, d_{80} / d_{20}$ and $\left.d_{90}-d_{10}\right) / d_{50}$, PSD width calculations showed that their values decreased with grinding process.

iv) FTIR analysis showed that there is a normal result for calcite. DTA results show that there was no an exothermic reaction in the calcite. TG curves demonstrate that the calcite has a layer situation. Electron microscopy (SEM) images of micronized calcite show that the surface of the calcite after grinding appears to be smooth and uniform.

v) The fuzzy statistical process control methods are very effective in the grinding plant of calcite.

\section{ACKNOWLEDGEMENTS}

The author wish to thank Nidaş limited company, Nigde/TURKEY and to their colleagues who participated and provided support in the work.

\section{REFERENCES}

[1]. T.W. Chenje, D.J. Simbi, E. Navara, Relationship Between Microstructure, Hardness, Impact Toughness and Wear Performance of Selected Grinding Media for Mineral Ore Milling Operations, Mater. Des. 25, 2004, 11-18.

[2]. B. Tamm, A. Tymanok, Impact Grinding and Disintegrators, Proc. Estonian Acad. Sci. Eng. 2/2 (1996), 209-242.

[3]. P. Kulua, R. Tarbea, H.D. Kaerdi, Abrasivity and Grindability Study of Mineral Ores, Wear, 267 (2009), $1832-1837$.

[4]. Katz. H. S. and Milewski. J. V. Eds.. Handbook of Fillers and Reinforcement for Plastics Van NostrandReinhold. NY. 1978.

[5]. H.P. Schreiber, J.M. Viau, A. Fetou and Z. Deng, Some Properties of Polyethylene Compounds with Surface-Modified Fillers, Polym. Eny. Sci. 30 (5), 1990, 263-269.

[6]. H. Murray, Industrial Clays Case Study. Report of the Mining. Minerals and Sustainable Development Project, International Institute for Environment and Development and World Business Council for Sustainable Development, 2002, 64.

[7]. R.G.Burns, Mineralogical Applications of Crystal Field Theory, Cambridge Topics in Minerals Physics and Chemistry, Second Edition, Cambridge Univ. Press. Cambridge, (1993).

[8]. R. Sharafudeen, The Manufacturing Process Parameters Affecting Color and Brightness of $\mathrm{TiO}_{2}$ Pigment, Int. J. Ind. Chem, 3, 2012, 1-7.

[9]. K. Theodora, L. Jennifer, F.M. John, Experiences with Industrial Applications Of Projection Methods for Multivariate Statistical Process Control, Computers Chem. Eng. 20, 1996, 745-750.

[10]. H. Ipek, H. Ankara, H. Ozdag, The Application of Statistical Process Control, Minerals Engineering. 12, 1999, 827-835. 
[11]. W.H Woodall, Controversies and Contradictions in Statistical Process Control, J. Qual. Technol. 32, 2000, 341-350.

[12]. M. Dudek-Burlıkowska, Using Control Charts X-R in Monitoring a Chosen Production Process, J. Achieve. Mater. Manufactur. Eng. 49, 2011, 487-498.

[13]. R. Filzmoser, R. Vertl, Testing Hypotheses with Fuzzy Data: The Fuzzy Pvalue, Metrika. 59, 2004, 2129.

[14]. R. Viertl, D. Hareter, Fuzzy Estimation and Imprecise Probability, Journal of Applied Mathematics and Mechanics, 84, 2004, 731-739.

[15]. M. Gülbay, C. Kahraman, An Alternative Approach to Fuzzy Control Charts: Direct Fuzzy Approach, Information Sciences, 177, 2007, 1463-1480.

[16]. A. Kanagawa, F. Tamaki, H. Ohta, Control Charts for Process Average and Variability Based On Linguistic Data, International Journal of Production Research, 31, 1993, 913-922.

[17]. N. Sugano, Fuzzy Set Theoretical Approach to Achromatic Relevant Color on The Natural Color System. International Journal of Innovative Computing, Information and Control. 2(1), 2006, 193-203.

[18]. M.H. Shu, C.W. Hsien, Fuzzy X And R Control Charts: Fuzzy Dominance Approach, Computers \& Industrial Engineering, 61, 2011, 676-685.

[19]. A. Duncan, A Chi-Square Chart for Controlling a Set of Percentages, Industrial Quality Control, 7, 1950, 11-15.

[20]. M. Marcucci, Monitoring Multinomial Processes, Journal of Quality Technology. 17, 1985, 86-91.

[21]. L.S. Nelson, A Chi-Square Control Chart for Several Proportions, Journal of Quality Technology, 19, 1987, 229-231.

[22] C.W. Bradshaw, A fuzzy Set Theoretic İnterpretation of Economic Control Limits, European Journal of Operational Research, 13, 1983, 403-408.

[23]. A Brief Introduction to Neural Networks. Available at http://www.varlikmakina.com/kompletesisler (accessed on May 20 st., 2010).

[24]. G.E. Christidis, N. Sakellariou, E.M. Repouskou, Influence of Organic Matter and Iron Oxides on the Colour Properties of a Micritic Limestone From Kefalonia, Bulletin of the Geological Society of Greece vol. XXXVI (2004), 72-79.

[25]. M.D. Fairchild, Color Appearance Models. Reading, Mass: Addison Wesley Longman, Inc. (1998).

[26]. British Standards Institution-BS3900. Parts D8. D9 and D10, Determination of Colour and Colour Difference: Principles, Measurement And Calculation, (1986).

[27]. M. Maskan, Kinetics of Color Change of Kiwifruits During Hot Air and Microwave Drying, Journal of Food Engineering, 48(2), 2001, 169-175.

[28]. R.C.L. Homco, K.J. Ryan, S.E. Wicklund, C.L. Nicolalde, S. Lin, F.K. Mckeith, Effects of Modified Corn Gluten Meal On Quality Characteristics of a Model Emulsified Meat Product, Meat Science,67, 2004, 335-341.

[29]. A. Joiner, I. Hopkinson, Y. Deng, S. Westlan, Review of Tooth Colour and Whiteness, Journal of Dentistry, 2008, 365.

[30]. C. Saricoban, M.T. Yilmaz, Modelling the Effects of Processing Factors on the Changes in Colour Parameters of Cooked Meatballs Using Response Surface Methodology, World Applied Sciences Journal, 9(1), 2010, 14-22.

[31]. A. Hanbury, The Taming of the Hue, Saturation and Brightness Colour Space, The Seventh Computer Vision Winter Workshop was held on February, 2002, 4-7.

[32]. F.J. Francis, F.M. Clydesdale, Food Colorimetry: Theory and Applications, Westport, CN: AVI Publishing, (1975).

[33]. R. Hirschler, Color in Food, Technological and Psychophysical Aspects, CRC, 2012, 93-104.

[34]. M. Maskan, Kinetics of Colour Change of Kiwifruits During Hot Air and Microwave Drying, Journal of Food Engineering, 2001, 48.

[35]. R.C.L. Homco, K.J. Ryan, S.E. Wicklund, C.L. Nicolalde, S. Lin, F.K. Mckeith et al., Effects of Modified Corn Gluten Meal On Quality Characteristics of A Model Emulsified Meat Product, Meat Science, 2004, 67.

[36]. A Brief Introduction to Neural Networks. Available at http://www.bessegato.com.br/UFJF /resources/table_of_control_chart_constants_old.pdf (accessed on November 29 st., 2016).

[37]. D.R. Prajapati, Implementation of SPC Techniques in Automotive Industry: A Case Study, International Journal of Emerging Technology and Advanced Engineering, 2(3), 2012, 227-241.

[38] . D.C. Montgomery, Introduction to Statistical Quality Control, New York: John 626 Wiley \& Sons, (2005)

[39]. M. Khademi, V. Amırzadeh, Fuzzy Rules For Fuzzy X and R Control Charts, Iranian Journal of Fuzzy Systems, 11(5), 2014, 55-66. 
[40]. V.E. Kane, Process Capability Indices, Journal of Quality Technology, 18, 1986, 41-52.

[41]. S. Kotz, N. Johnson, Process Capability Indices - A review 1992-2000. Journal of Quality Technology, 34, 2002, 2-19.

[42]. I. Kaya, C. Kahraman, Process Capability Analyses Based on Fuzzy Measurements and Fuzzy Control Charts, Expert Systems with Applications, 38, 2011, 3172-3184.

[43]. C.C. Tsai, C.C. Chen, Making Decision to Evaluate Process Capability Index Cp with Fuzzy Numbers, International Journal of Advanced Manufacturing Technology, 30, 2006, 334-339.

[44]. H. Karbstein, F. Muller, R. Polke, Producing Suspensions with Steep Particle Size Distributions in Fines Ranges, Aufbereitungs-Technik 36, 1995, 464-473.

[45]. H. Karbstein, F. Muller, R. Polke, Scale-up for Grinding in Stirred Ball Mills, Aufbereitungs-Technik, 37, 1996, 469-479.

[46]. A.D. Salman, C.A. Biggs, J. Fu, I. Angyal, M. Szabo, M.J. Hounslow, An Experimental Investigation of Particle Fragmentation Using Single Particle Impact Studies, Powder Technology, 128, 2002, 36-46.

[47]. D.A. Gorham, A.D. Salman, M.J. Pitt, Static and Dynamic Failure of PMMA Spheres, Powder Technology, 138, 2003, 229-238.

[48]. G. Matija, S. Kurajica, Grinding Kinetics of Amorphous Powder Obtained by Sol-Gel Process, Powder Technology 197, 2010, 165-169.

[49]. Karbstein H, Muller F, Polke R. Scale-up for grinding in stirred ball mills. Aufbereitungs-Technik. 1996:37:469-479.

[50]. M. Nakacha, J.R. Authelina, A. Chamayoub, J. Dodds, Comparison of Various Milling Technologies for Grinding Pharmaceutical Powders, International Journal of Mineral Processing 74, 2004, 173-181.

[51]. H. Adi, I. Larson, P. Stewart, Use of Milling and Wet Sieving to Produce Narrow Particle Size Distribution of Lactose Monohydrate in The Sub-Sieve Range, Powder Technology, 179, 2007, 95-99.

[52] A Brief Introduction to Neural Networks. Available at

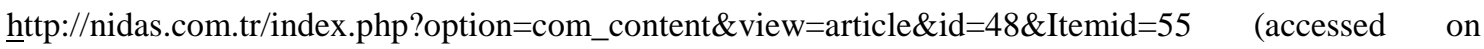
November 30 st., 2016).

[53]. K.A.R. Gomari, A.A.Hamouda, R. Denoyel, Influence of Sulfate Ions on the Interaction Between Fatty Acids and Calcite Surface, Colloids Surf. A: Physicochem. Eng. Aspects, 287, 2006, 29-35.

[54]. S.D. Cifrulak, High-Pressure Mid-İnfrared Studies of Calcium Carbonate, Amer. Mineral, 55, 1970, 815824.

[55]. A Brief Introduction to Neural Networks. Available at https://www.labtesting.com/services/materialstesting/metallurgical-testing/sem-analysis/ (accessed on November 29 st. 2016). 